\title{
Efecto de los gusanos de terciopelo (Onychophora) en la cultura y arte durante el periodo 2014-2019; representaciones, temáticas y distribución mundial
}

\author{
Andrés Arias-Paco ${ }^{1}$ \\ 1. Universidad de Costa Rica, Escuela de Biología, San José, Costa Rica; andres.ariaspaco@ucr.ac.cr \\ Recibido 12-II-2020 • Corregido 03-IV-2020 • Aceptado 07-IV-2020 \\ DOI: https://doi.org/10.22458/urj.v12i1.2798
}

\begin{abstract}
Effect of velvet worms (Onychophora) on culture and art during the period 2014-2019; representations, subjects and worldwide distribution". Introduction: Velvet worms are a terrestrial invertebrate group, considered "living fossils" by some, with over 520 million years of existence. They capture prey with a sticky secretion, and some species have a placenta. By being animals with such peculiar features, but not traditionally selected as "charismatic species", it is interesting to see the cultural and artistic influence that they currently may have. Objective: This research reports how the phylum Onychophora has influenced culture and art in the years after the study by Monge-Nájera \& Morera-Brenes five years ago. Methods: I searched the cultural and artistic works related to Onychophora on the web, through the most common names these animals receive in different countries, to assess if the number of products has increased. Furthermore, I classified the works in subjects and according to positive or negative depictions. Results: I found 336 cultural and artistic works related to Onychophora, most of them cartoons, then sublimated products, craftworks, edited images and videos. I also found 6 outstanding subjects, and in most of the cases, the works carry a positive image. The countries with the most total works are the United States, Australia and New Zealand, while per capita (per million inhabitants) are New Zealand, Costa Rica and Australia. Conclusions: The onychophore's external morphology mainly, along with their hunting mechanism, have generated an unexpected interest in culture and arts.
\end{abstract}

Keywords: Velvet worms, oral papillae, anthropomorphism, charismatic species, invertebrates in culture.
RESUMEN. Introducción: Los gusanos de terciopelo son un grupo de invertebrados actualmente terrestres, que se consideran fósiles vivientes, con más de 520 millones de años de existir. Su forma de caza consiste en el disparo de una goma pegajosa que envuelve a sus víctimas, y algunas especies tienen placenta. Al ser animales con características tan peculiares, pero que tradicionalmente no entran en la categoría de "especies carismáticas", es interesante la influencia cultural y artística que actualmente puedan tener. Objetivo: Esta investigación tiene como objetivo ver cómo ha influenciado Onychophora la cultura y arte en los años posteriores al estudio de Monge-Nájera \& Morera-Brenes (2015). Métodos: Busqué las producciones culturales y artísticas relacionadas a Onychophora en la web, mediante los nombres más comunes que reciben estos animales en diferentes países, para observar si la cantidad de producciones ha aumentado. Además, clasifiqué las producciones en temas y de acuerdo al tipo de impresión (positiva o negativa). Resultados: Encontré 336 producciones culturales y artísticas relacionadas a Onychophora, de las cuales la mayoría corresponden a dibujos animados, luego a productos sublimados, artesanías, imágenes editadas y videos. También encontré 6 temas sobresalientes, y en la mayoría de casos, las producciones transmiten una imagen positiva. Los países con mayor producción en total son Estados Unidos, Australia y Nueva Zelanda, mientras que per cápita (por millón de habitantes) son Nueva Zelanda, Costa Rica y Australia. Conclusión: La morfología externa de los onicóforos principalmente, junto con su método de caza, ha generado un interés inesperado en la cultura y arte.

Palaras clave: Gusanos de terciopelo, papilas orales, antropomorfismo, especies carismáticas, invertebrados en la cultura. 
Los gusanos de terciopelo (Filo Onychophora), son invertebrados terrestres con cuerpos blandos sumamente sensibles a la deshidratación, con hábitos principalmente nocturnos para evitar la desecación (Monge-Nájera, Barrientos, \& Aguilar, 1993; McDonald \& Daniels, 2012). Buscan lugares húmedos y oscuros, como troncos en descomposición, debajo de la hojarasca, dentro de microcavernas y generalmente cerca de algún cauce de agua (Monge-Nájera \& Hou, 1999; Vasconcellos, Almeida, \& Souza, 2006; Espinasa et al., 2015). Su forma de caza es única, ya que enredan a sus presas, que generalmente son invertebrados pequeños, con un material pegajoso que disparan a través de dos papilas orales (Lavallard \& Campiglia, 1971; Benkendorff, Beardmore, Gooley, Packer, \& Tait, 1999; Monge-Nájera \& Hou, 1999). Luego proceden a romper la cutícula del animal inmóvil e inyectar saliva digestiva y succionar a la presa (Read \& Hughes, 1987; Monge-Nájera \& Hou, 1999; Morera-Brenes, 2012; Mayer et al., 2015).

En los trópicos (Familia Peripatidae) presentan una placenta completa, siendo los únicos invertebrados con dicho órgano (Monge-Nájera, 1995; Monge-Nájera, Barquero-González, \& Morera-Brenes, 2019). Además, tienen gran valor científico, porque su morfología ha variado muy poco a lo largo de 520 millones de años aproximadamente, por lo que se consideran fósiles vivientes, junto con el hecho de que se piensa que fueron los primeros animales en poder caminar (MongeNájera \& Hou, 1999; Morera-Brenes, 2012).

Históricamente existe un mayor apego y valoración hacia los vertebrados, lo que se ve reflejado en la mayoría de programas de conservación, que dejan por fuera a los invertebrados o los incluyen pobremente (Dunn, 2005). A pesar de este fuerte sesgo, ciertos grupos de invertebrados inspiran el arte y la cultura humana, influyendo fuertemente en obras literarias, películas, pinturas y personajes ficticios, tanto en series de televisión como en comic's (CupulMagaña, 2011; Da-Silva \& Coelho, 2016). Incluso se ha registrado su influencia en los proverbios culturales que se transmiten oralmente en ciertas comunidades de España (Santiago-Álvarez, 2014). Se han observado representaciones artísticas de odonatos grabados en diversos materiales, así como pequeñas esculturas de piedra o madera de los mismos (Vázquez \& Callejas, 2002). También se utilizan en imágenes de estampillas, sellos y sobres (Palacios-Vargas, 2011). Dentro de la arquitectura presentan una notable influencia, ya que lepidópteros, ortópteros e himenópteros son muy comunes en la decoración externa o interna de edificios, así como en la construcción de los mismos (Blas \& Del Hoyo, 2013). Por último, algunos grupos de invertebrados se han relacionado culturalmente con la alimentación de los humanos desde tiempos muy antiguos (Viesca-González \& Romero-Contreras, 2009).

A pesar de que los onicóforos son animales tan interesantes debido a las características anteriormente descritas, no son comunes de observar, inclusive dentro del ámbito científico, ya que no muchos biólogos han podido observar alguno vivo y menos en su hábitat natural (Monge-Nájera \& Hou, 1999). Sin embargo, estos animales también tienen una influencia cultural y artística en las personas, ya que han inspirado dibujos animados, canciones o bandas que llevan su nombre, anuncios de agencias turísticas y productos que utilizan imágenes de los mismos, así como creencias folclóricas, poemas y otros tipos de arte (Monge-Nájera \& Morera-Brenes, 2015).

Los gusanos de terciopelo han resultado ser un grupo que genera empatía en las personas, así lo indica el único estudio realizado hasta la fecha sobre el efecto cultural y artístico de un fósil viviente (Monge-Nájera \& Morera-Brenes, 2015). Probablemente la magnitud del impacto en la cultura y arte que ha tenido Onychophora, ha aumentado considerablemente en los años posteriores a dicho estudio, trayendo una nueva serie de representaciones artísticas y culturales no descritas hasta ahora. Por tanto, este estudio investiga cómo ha influenciado Onychophora la cultura y arte desde el año 2014 hasta el 2019. 


\section{MATERIALES Y MÉTODOS}

Realicé una búsqueda de referencias culturales y artísticas relacionadas a Onychophora en Facebook del 5 al 14 de agosto, el 1 o de septiembre y el 8 de octubre, en Instagram del 8 de julio al 3 de octubre, en Twitter del 12 al 17 de agosto y el 10 de septiembre del 2019. En dichas redes busqué publicaciones con las etiquetas epiperipatus, peripatopsidae, eoperipatustotoro, peripatus, metaperipatus, onicoforo, velvet worm, stummelfüBer, velvet worms, onicóforos, onychophora, onychophoran, onychophorans y gusanos de terciopelo. Además, busqué publicaciones con estos términos en DeviantArt, FurAffinity, Tumblr y en el motor de búsqueda de google.com, desde el 14 de agosto del 2019 hasta el 3 de octubre del mismo año.

Tomé en cuenta solamente las producciones artísticas y culturales que no tuvieran un fin meramente académico, sino sólo artístico, por lo que descarté dibujos científicos para revistas o animaciones académicas, ya que no era parte de la investigación. Además, descarté todas las producciones artísticas y culturales ya descritas anteriormente por Monge-Nájera y Morera-Brenes (2015), para evitar datos repetidos. Así mismo, eliminé datos que presentaban errores de interpretación o conocimiento, como relaciones entre el título "gusanos de terciopelo" con larvas de lepidópteros y no con onicóforos, siendo uno de los errores de interpretación más común. Clasifiqué las producciones encontradas según el tipo de material artístico, año en que fue producido, país de origen, tema de la producción e impresión, fuera positiva o negativa. Catalogué como impresión positiva si transmitían una imagen favorable de los onicóforos o bien, sentimientos humanamente valorados como agradables (amor, amistad y paz), mientras que, si transmitían una imagen de terror, miedo, parasitismo o veneno, los catalogué de impresión negativa. Clasifiqué las producciones en grandes temas, según las características que presentaban las mismas. Si presentaban a los onicóforos de una forma cercana a la realidad en cuanto a su morfología o comportamiento se clasificaban como onicóforos de forma realista, si los presentaban como personajes mitológicos o con elementos de fantasía se clasificaban como onicóforos ficticios, si los presentaban con características exclusivamente humanas en cuanto al comportamiento, se clasificaban como onicóforos humanizados. Otras producciones los presentaban como onicóforos homosexuales o lesbianas, por lo que se clasificaron como relacionado a la comunidad LGBTIQ. Mientras que, si presentaban a los onicóforos fusionados con el ser humano o con otros organismos, se clasificaban como híbridos entre onicóforos y humanos o híbridos con organismos no humanos, según fuera el caso. Además, envié mensajes directos a aproximadamente 90 autores de diferentes producciones artísticas y culturales, para obtener información directa de cómo conocieron de los onicóforos, su impresión sobre ellos, que tan populares son en su país, y la razón por la que realizaron un arte basado en los mismos. En otros casos, las producciones culturales y artísticas venían con descripciones donde especificaban este tipo de datos, por lo que no hubo necesidad de enviar mensajes a los autores.

Realicé un análisis en bruto y per cápita de la cantidad de producciones encontradas en los países donde existía material artístico y cultural de onicóforos, para llevar a cabo una comparación con lo encontrado anteriormente por Monge-Nájera y Morera-Brenes (2015). Además, realicé la prueba de chi cuadrado, para comprobar si la cantidad de producciones varía en los años, con hipótesis nula de que todos los años presentan misma cantidad de producciones. Para esto agrupé los años en 4 periodos, de 1982 a 2007, de 2008 a 2011, de 2012 a 2015 y de 2016 a 2019. Igualmente utilicé dicha prueba, para ver si la cantidad de producciones varía entre los temas sobresalientes, con hipótesis nula de que todos los temas presentan la misma cantidad de producciones.

Ética, conflicto de intereses y declaración de financiamiento: El autor declara haber cumplido con todos los requisitos éticos y legales pertinentes, tanto durante el estudio como en el 
manuscrito; que no hay conflictos de interés de ningún tipo, y que todas las fuentes financieras se detallan plena y claramente en la sección de agradecimientos. Asimismo, está de acuerdo con la versión editada final del documento. El respectivo documento legal firmado se encuentra en los archivos de la revista.

\section{RESULTADOS}

Se encontraron 336 producciones culturales y artísticas relacionadas a Onychophora (Fig. 1). Este hallazgo muestra que, respecto a lo encontrado por Monge-Nájera y Morera-Brenes (2015), ha ocurrido un aumento significativo en los últimos 6 años $\left(x^{2}=364.26, \mathrm{gl}=3, \mathrm{p}<0.05\right)$, ubicando los picos más altos de producciones en los años 2017, 2018 y 2019 (Fig. 2).

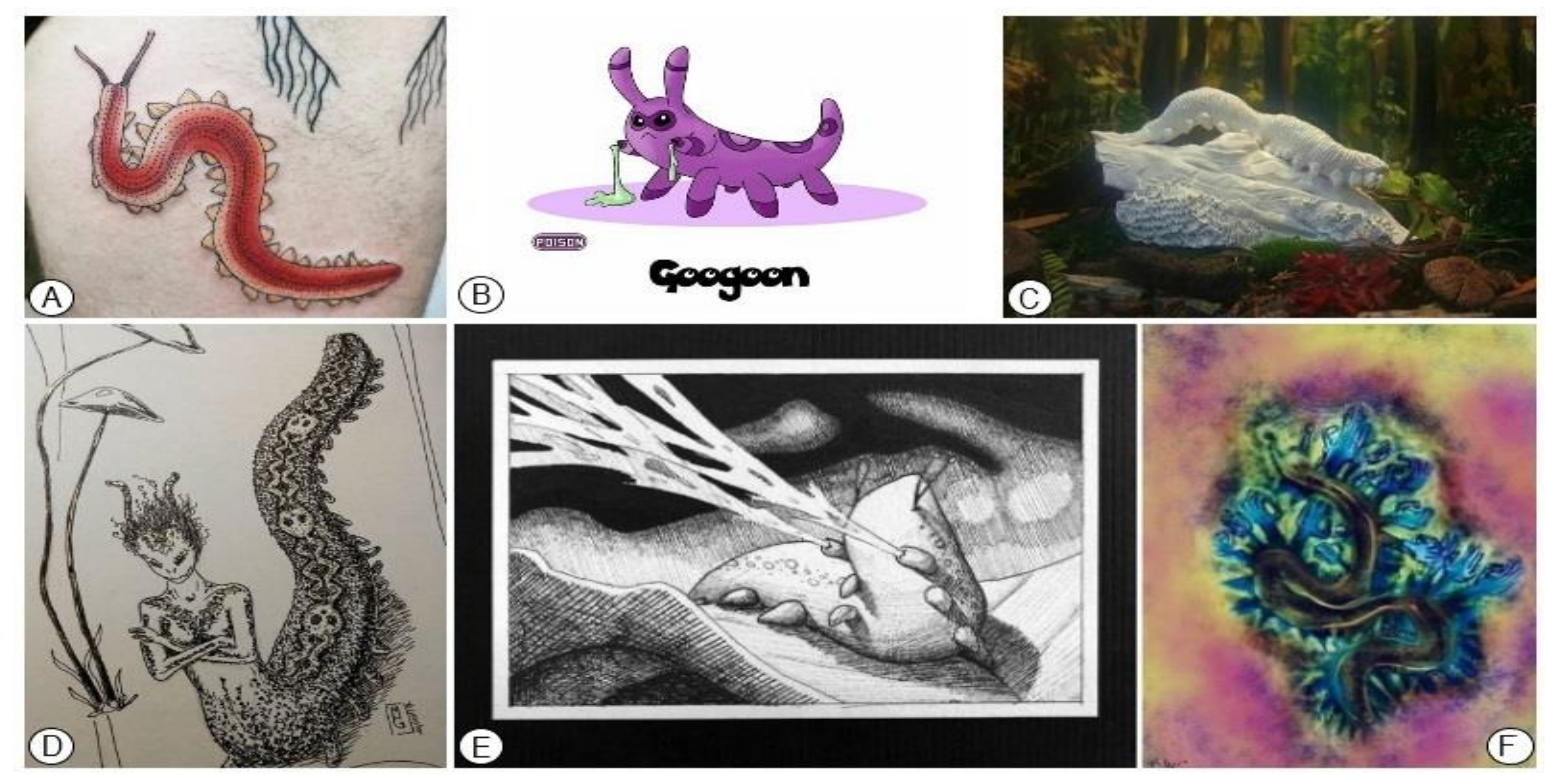

Fig. 1. Muestras representativas de las producciones artísticas y culturales de Onychophora. A. Tatuaje de Nicolas Bekkouche (La Douce, 2019). B. Diseño de fakemon (Deglmann, 2019) C. Diorama de gusanos de terciopelo (Kelly, 2017). D. Diseño de híbrido de onicóforo (Gélineau, 2017). E. Arte de onicóforo disparando la goma (Joshuacarterart, 2019). F. Pintura de onicóforo realizada por la antropóloga evolutiva Kathleen Bryson (Bryson, 2017).

Del total de producciones culturales y artísticas se encontraron seis temas principales (Fig. 3 ), de los cuales un primer y mayor grupo presenta a los onicóforos de una forma cercana a la realidad $\left(x^{2}=62,36, g l=5, p<0,05\right)$. Un segundo grupo los presenta con características ficticias, en donde se habla de "el dios de la vida", que es un personaje mitológico basado en onicóforos (Popcornflavoredtea, 2018) o bien "Eclipatus" que es un onicóforo creador de la primera noche, para salvar a los que sufren de calor (SkarmorySilver, 2018), hasta onicóforos que presentan alas y pueden volar (NosoyRidley, 2016). Por otro lado, el tercer grupo los presenta de forma humanizada, en donde se encuentran desde onicóforos que utilizan prendas de vestir como zapatos o abrigos (Gemma_gem3343, 2019) hasta onicóforos fumando y relajándose (Sobeyondthis, 2011), mientras que los híbridos entre onicóforos y humanos constituyen un cuarto grupo. En un quinto lugar, se encuentran las producciones relacionadas con la comunidad LGBTIQ, en donde hay casos de onicóforas lesbianas (Methipids, 2018). Por último, el sexto grupo se enfoca en el tema de híbridos de onicóforos con organismos no humanos, en donde se encuentran desde onicóforos fusionados con nudibranquios (Ink--It, 2016) hasta híbridos entre onicóforos con hongos (Mycotae, 2019). 
100

0

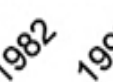

Año

Fig. 2. Comparación del número de producciones culturales y artísticas de Onychophora encontradas en la actualidad* respecto a lo encontrado por Monge-Nájera y Morera Brenes (2015) $\left(x^{2}=364,26, \mathrm{gl}=3, \mathrm{p}<0,05\right) .{ }^{*}$ Las producciones encontradas en el 2019 llegan hasta el 3 de octubre de dicho año, por lo que no contempla las producciones realizadas en los meses restantes.

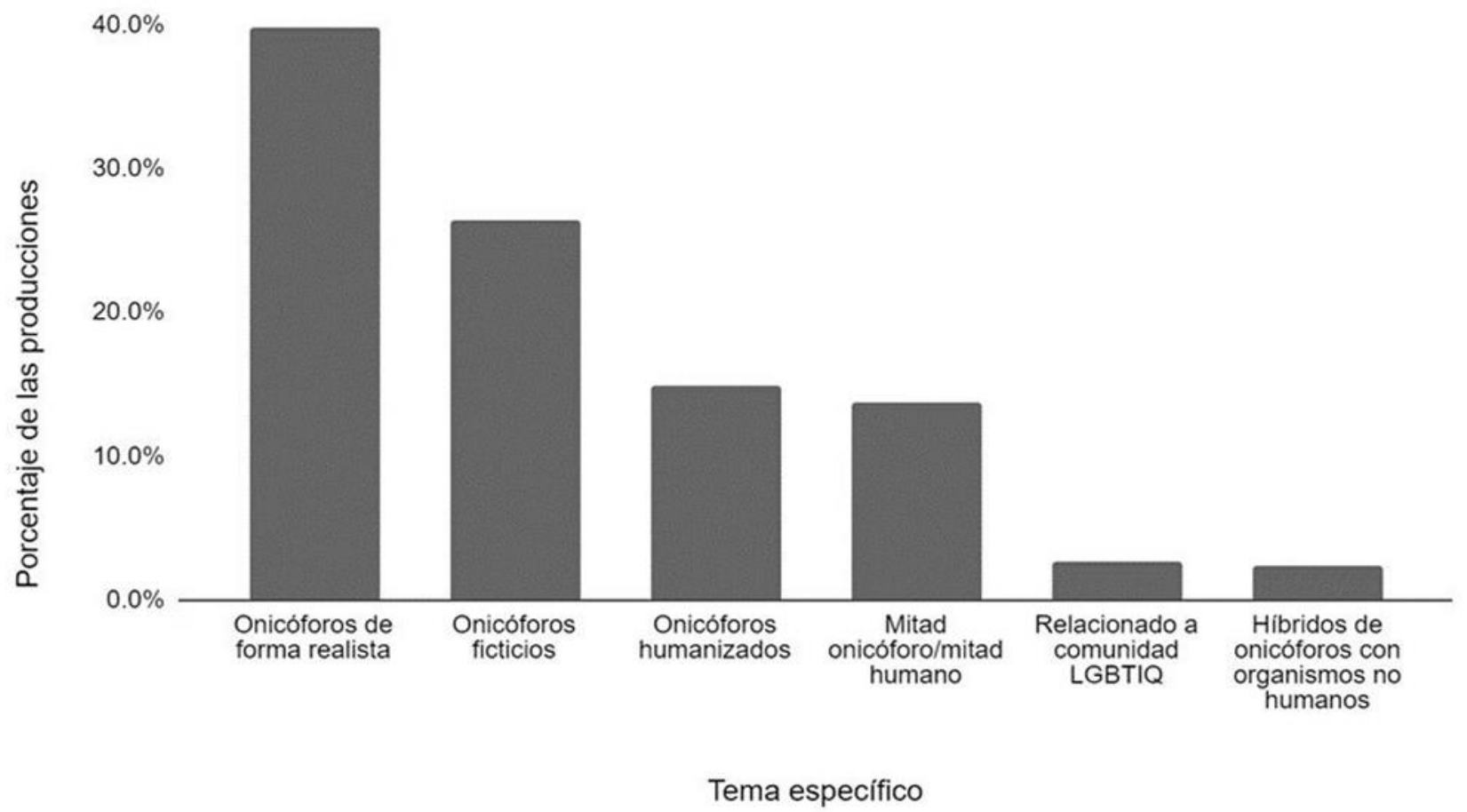

Fig. 3. Principales temas encontrados en las producciones artísticas y culturales de Onychophora con el respectivo porcentaje que cada una representa $\left(x^{2}=62,56, g \mid=5, p<0,05\right)$. 


\section{CUADRO 1}

Países con producciones artísticas y culturales de Onychophora

\begin{tabular}{|c|c|c|c|c|}
\hline Puesto & País & $\begin{array}{l}\text { Número de producciones } \\
\text { en total }\end{array}$ & País & $\begin{array}{l}\text { Número de producciones por } \\
\text { millón de habitantes }\end{array}$ \\
\hline 1 & Estados Unidos & 159 & Nueva Zelanda & 4,39 \\
\hline 2 & Australia & 22 & Costa Rica & 1,58 \\
\hline 3 & Nueva Zelanda & 21 & Australia & 0,87 \\
\hline 4 & Canadá & 18 & Suecia & 0,5 \\
\hline 5 & Reino Unido & 15 & Estados Unidos & 0,48 \\
\hline 6 & Japón & 12 & Canadá & 0,48 \\
\hline 7 & Costa Rica & 8 & Países Bajos & 0,23 \\
\hline 8 & Suecia & 5 & Reino Unido & 0,22 \\
\hline 9 & Francia & 5 & Dinamarca & 0,17 \\
\hline 10 & Alemania & 5 & Austria & 0,11 \\
\hline 11 & Países Bajos & 4 & Japón & 0,094 \\
\hline 12 & Islandia & 3 & República Checa & 0,09 \\
\hline 13 & Finlandia & 3 & Francia & 0,077 \\
\hline 14 & República de Corea & 2 & Alemania & 0,06 \\
\hline 15 & Colombia & 2 & Rumanía & 0,052 \\
\hline 16 & Italia & 2 & Chile & 0,05 \\
\hline 17 & Polonia & 1 & República de Corea & 0,04 \\
\hline 18 & Caribe & 1 & Colombia & 0,04 \\
\hline 19 & Argentina & 1 & Italia & 0,03 \\
\hline 20 & España & 1 & Polonia & 0,026 \\
\hline 21 & Tailandia & 1 & Caribe & 0,023 \\
\hline 22 & México & 1 & Argentina & 0,022 \\
\hline 23 & Rusia & 1 & España & 0,021 \\
\hline 24 & Indonesia & 1 & Tailandia & 0,014 \\
\hline 25 & India & 1 & México & 0,008 \\
\hline 26 & Antártida & 1 & Rusia & 0,007 \\
\hline 27 & Dinamarca & 1 & Indonesia & 0,004 \\
\hline 28 & Austria & 1 & India & 0,00073 \\
\hline 29 & República Checa & 1 & Islandia** & 8,84 \\
\hline 30 & Rumanía & 1 & Finlandia** & 0,54 \\
\hline 31 & Chile & 1 & & \\
\hline
\end{tabular}

**Para evitar errores a la hora de analizar los países con mayor producción per cápita, no se tomaron en cuenta datos extremos (países con menos de 5 producciones). 
Los cinco países con mayor producción cultural y artística en total son Estados Unidos, seguido de Australia, Nueva Zelanda, Canadá y Reino Unido. Luego se encuentran países como Japón, Costa Rica, Suecia, Francia y Alemania, todos con cinco o más producciones. Per cápita (por millón de habitantes), Nueva Zelanda es el país con mayor producción cultural y artística, seguido de Costa Rica, Australia, Suecia y Estados Unidos que comparte la quinta posición con Canadá, por encima de Países Bajos, y Reino Unido (Cuadro 1).

La mayor cantidad de producciones artísticas y culturales corresponden a dibujos animados, seguidos por productos sublimados (camisetas, jarras, bolsos, estuches de celulares y similares), artesanías, imágenes editadas y videos. Además, la mayoría de producciones transmiten una imagen positiva sobre los onicóforos, solo un $13,4 \%$ transmiten una imagen negativa. En los híbridos de onicóforos con organismos no humanos, un $38 \%$ de las producciones deja una imagen negativa, siendo el tema con mayor porcentaje negativo, mientras que las producciones relacionadas a la comunidad LGBTIQ no presentan producciones que transmitan una imagen negativa.

\section{DISCUSIÓN}

El aumento en la cantidad de producciones artísticas y culturales de Onychophora desde el 2014 hasta el 2019, se puede explicar por una mayor exposición de estos animales en la cultura popular que en años pasados. El documental grabado por la BBC en el 2005 continúa siendo el principal referente para inspirar este tipo de producciones tal y como lo mencionaron Monge-Nájera y Morera-Brenes (2015), sin embargo, no es el único. Los documentales de Monster Bug Wars transmitidos en el 2012 en Science Channel de Discovery, donde presentan un onicóforo cazando un opilión (https://www.sciencechannel.com/tv-shows/monster-bug-wars/), y el documental del canal de YouTube Brave Wilderness en el 2017, en el que encuentran la especie de onicóforo gigante Peripatus solorzanoi en Costa Rica (https://www.youtube.com/watch?v=42G_XzaPcPo\&t=325s), han sido referentes para esta explosión de producciones. En segundo plano, leer sobre los onicóforos en libros, verlos personalmente, estudiarlos en cursos universitarios, y buscar animales invertebrados viscosos en la web, han sido otras formas que han inspirado este aumento artístico y cultural.

De los temas encontrados, el presentar a los onicóforos de forma cercana a la realidad o de forma ficticia, se explica por su apariencia, mostrada o descrita en la mayoría de producciones como "alienígena", "sorprendente", "tierna" o "rara", y por su forma de caza única. Esto genera que sean muy interesantes para las personas, sin necesidad de agregar elementos ficticios. Y aunque parezca contradictorio, también ambos factores dan lugar a lo ficticio. El disparo de goma, motiva creaciones de onicóforos que expulsan lava volcánica o hielo que nunca se derrite, mientras que la apariencia motiva producciones de onicóforos de tamaño desproporcionado. Los onicóforos humanizados también son un tema presente, en parte porque el ser humano está acostumbrado a antropomorfizar (Salcedo, 2010). Pero generalmente no suele humanizar animales que no le son similares en apariencia, excluyendo a muchos invertebrados de dicha práctica (Batt, 2009). Los onicóforos son una excepción a esta tendencia, y proponer que esto se debe a características compartidas con humanos como la placenta en hembras (en Peripatidae) o comportamiento social, es poco probable, porque la mayoría de personas no conocen esta información, sino que su fuente de conocimiento suelen ser los documentales donde generalmente se omiten este tipo de datos. Su apariencia diferente a nosotros, pero vista positivamente juega un papel importante en esta humanización, incluso más que su método de caza.

Los híbridos de onicóforos con humanos fue otro tema recurrente. En el mito del minotauro, la animalidad y el desenfreno juegan un papel importante, que resulta en una vergüenza a la vista (Camacho, 1996). Por el contrario, la mayoría de casos de híbridos entre onicóforos y 
humanos, no se relacionan con la animalidad ni el desenfreno, sino que se perciben como algo tierno y aceptable a la vista, hasta cierto punto romántico y sensual, lo cual se puede atribuir a la apariencia de los onicóforos, que en general es vista agradablemente. El tema de híbridos de onicóforos con otros organismos no humanos, presenta el porcentaje más alto de impresiones negativas. Sin embargo, es poco probable que se deba por los onicóforos, ya que específicamente son híbridos que presentan vampiros, iconos relacionados con el temor (Solaz, 2003), o bien arañas, que suelen ser animales temidos popularmente (Bermúdez-Ornelas \& Hernández-Guzmán, 2008). El tema de onicóforos relacionados con la comunidad LGBTIQ, posiblemente se deba a que son animales poco comunes y no catalogados como populares, por lo que personas de grupos minoritarios se pueden sentir identificados con ellos. Además, es el único tema que presenta todas sus producciones de manera positiva, lo que se explica debido a que buscan mostrar sin discriminación a dicha comunidad.

Estados Unidos continúa siendo el país con mayor cantidad en total de producciones. Monge-Nájera y Morera-Brenes (2015) explicaron que esta tendencia se debe a la enorme población e industria cultural en dicho país. Nueva Zelanda, Costa Rica y Australia (todos con onicóforos) son los países que tienen mayor cantidad de producciones por millón de habitantes. Las personas de estos países en ocasiones han encontrado onicóforos, lo que ha inspirado producciones artísticas y culturales (Sharon Jones, comunicación personal 2019), o bien, les toman fotografías o videos que son subidos a redes sociales, lo que puede aumentar su difusión a nivel local. En Dunedin, Nueva Zelanda se han elaborado juguetes de onicóforos para crear conciencia ecológica (Tanya Marriot, comunicación personal 2019), así como talleres artísticos para niños, donde hacen esculturas de onicóforos (the_art_department, comunicación personal 2019), producto del fuerte impacto que tienen en este país.

En conclusión, principalmente la morfología externa de los onicóforos, junto con su método de capturar presas, han despertado un interés inesperado, lo que se refleja en la enorme cantidad de producciones y las temáticas que estas presentan. Además, las producciones artísticas y culturales sobre onicóforos, pueden convertirse en un medio para que más personas se interesen en especies no carismáticas, específicamente de invertebrados.

\section{AGRADECIMIENTOS}

Agradezco a Julián Monge-Nájera por su constante ayuda, supervisión y sugerencias para la elaboración de esta investigación y para la redacción de este artículo. Además, agradezco a Akiko Futaki por la información brindada, así como a Nicolas Bekkouche, Ama La Douce, Christian Deglmann, Madison Kelly, Marina Gélineau, Joshua Carter y Kathleen Bryson, por permitirme usar sus producciones artísticas con su respectiva información para mostrarlas en la figura 1.

\section{REFERENCIAS}

Batt, S. (2009). Human attitudes towards animals in relation to species similarity to humans: A multivariate approach. Bioscience horizons, 2(2), 180-190. DOI: 10.1093/biohorizons/hzp021

Benkendorff, K., Beardmore, K., Gooley, A. A., Packer, N. H., \& Tait, N. N. (1999). Characterisation of the slime gland secretion from the peripatus, Euperipatoides kanangrensis (Onychophora: Peripatopsidae). Comparative Biochemistry and Physiology Part B: Biochemistry and Molecular Biology, 124(4), 457-465. DOI: 10.1016/s03050491(99)00145-5

Bermúdez-Ornelas, G., \& Hernández-Guzmán, L. (2008). Tratamiento de una sesión de la fobia específica a las arañas en niños. International Journal of Clinical and Health Psychology, 8(3), 779-791. Recuperado de https://www.redalyc.org/pdf/337/33712016011.pdf 
Blas, M., \& Del Hoyo, J. (2013). Entomología cultural y conservación de la biodiversidad: Los insectos en las Artes Mayores. Cuadernos de Biodiversidad, 42, 1-22. DOI: 10.14198/cdbio.2013.42.01

Bryson, K. (2017). Onychophora with Blue Human Hands [Pintura en Instagram] Recuperado de https://www.instagram.com/p/BelmBePlgF_/.

Camacho, D. C. (1996). En el centro del laberinto: la hybris y el Minotauro. Convivium, 2(9), 38-48.

Cupul-Magaña, F.G. (2011). El ciempiés como parte de diversas expresiones culturales alrededor del mundo. En: J.L. Navarrete-Heredia, G. Castaño-Meneses, \& G.A. Quiroz-Rocha (Eds.), Facetas de la Ciencia: ensayos sobre entomología cultural (pp. 11-14). Recuperado de https://insectosuson.files.wordpress.com/2012/02/entomologia_cultural_np.pdf

Da-Silva, E.R., \& Coelho, L.B.N. (2016). Zoologia Cultural, com ênfase na presença de personagens inspirados em artrópodes na cultura pop. En: E.R. Da-Silva, M.I.S. Passos, V.M. Aguiar, C.S.S. Lessa, \& L.B.N. Coelho (Eds.), Anais do III Simpósio de Entomologia do Rio de Janeiro (pp. 24-34). Recuperado de https://www.academia.edu/25180641/ZOOLOGIA_CULTURAL_COM_\%C3\%8ANFASE_NA_PRESEN\%C3\%87A_D E_PERSONAGENS_INSPIRADOS_EM_ARTR\%C3\%93PODES_NA_CULTURA_POP

Deglmann, C. (29 de julio de 2019). Ein neues Pokemon basierend auf dem Stummelfüßler, einen total abgefahrenen Wurm mit Beinen, der Schleim schießen kann [Diseño de fakemon en Instagram]. Recuperado de https://www.instagram.com/p/B0hDrytoATA/?igshid=10ynj43ssou2x.

Dunn, R. R. (2005). Modern insect extinctions, the neglected majority. Conservation biology, 19(4), 1030-1036. DOI: 10.1111/j.1523-1739.2005.00078.x

Espinasa, L., Garvey, R., Espinasa, J., Fratto, C. A., Taylor, S., Toulkeridis, T., \& Addison, A. (2015). Cave dwelling Onychophora from a Lava Tube in the Galapagos. Subterranean Biology, 15, 1-10. DOI: 10.3897/subtbiol.15.8468

Gélineau, M. (11 de octubre de 2017). I won't run, I'm more dangerous than you are [Dibujo en Instagram]. Recuperado de https://www.instagram.com/p/BaGxltiHetn/

Gemma_gem3343. (8 de enero de 2019). [Dibujo en Instagram]. Recuperado de https://www.instagram.com/p/BsXuLsvg4_l/

Ink--It. (15 de diciembre de 2016). Glow - Spits Shooting Animation [Dibujo animado en blog de arte]. Recuperado de https://www.deviantart.com/ink--it/art/Glow-Spits-Shooting-Animation-651482534

Joshuacarterart (24 de abril de 2019). The velvet worm [Dibujo en Instagram]. Recuperado de https://www.instagram.com/p/BwozYJUJ-63/?igshid=1rrOnywik4mc2

Kelly, M. (20 de abril de 2017). Study diorama for the Dunedin Velvet Worm population [Diorama en Instagram]. Recuperado de https://www.instagram.com/p/BTIT6hUhriu/?igshid=1xovk9pimq4mk

La Douce, A. (4 de septiembre de 2019). Ceci est un onychophore ou velvet worm pour les intimes [Tatuaje de onicóforo en Instagram] Recuperado de https://www.instagram.com/p/B1_wfjxifot/?igshid=1hkz3wdpspxuo

Lavallard, R., \& Campiglia, S. (1971). Données cytochimiques et ultrastructurales sur les tubes sécréteurs des glandes de la glu chez Peripatus acacioi Marcus et Marcus (Onychophore). Zeitschrift für Zellforschung und mikroskopische Anatomie, 118, 12-34. DOI: 10.1007/bf00331764

Mayer, G., Oliveira, I. S., Baer, A., Hammel, J. U., Gallant, J., \& Hochberg, R. (2015). Capture of prey, feeding, and functional anatomy of the jaws in velvet worms (Onychophora). Integrative and comparative biology, 55(2), 217-227. DOI: 10.1093/icb/icv004 
McDonald, D. E., \& Daniels, S. R. (2012). Phylogeography of the Cape velvet worm (Onychophora: Peripatopsis capensis) reveals the impact of Pliocene/Pleistocene climatic oscillations on Afromontane forest in the Western Cape, South Africa. Journal of evolutionary biology, 25(5), 824-835. DOI: 10.1111/j.1420-9101.2012.02482.x

Methipids. (25 de junio de 2018). Onychophora [Dibujo animado en blog de arte]. Recuperado de https://methipids.tumblr.com/post/175259511231/30-day-phyla-challenge-day-25-onychophora-trying

Monge-Najera, J. (1995). Phylogeny, biogeography and reproductive trends in the Onychophora. Zoological Journal of the Linnean Society, 114(1), 21-60. DOI: 10.1111/j.1096-3642.1995.tb00111.x

Monge-Nájera, J., Barquero-González, P., \& Morera-Brenes, B. (2019). Moda retro: ¿abandonaron los onicóforos el ovoviviparismo para volver a poner huevos? Revista de Biología Tropical, Columna Darwin In Memoriam.

Monge-Nájera, J., Barrientos, Z. \& Aguilar, F. (1993). Behavior of Epiperipatus biolleyi (Onychophora: Peripatidae) under laboratory conditions. Revista de Biología Tropical, 41, 689-696.

Monge-Nájera, J., \& Hou, X. (1999). 500 Millones de años de evolución: onicóforos, los primeros animales que caminaron (Onychophora). Boletín SEA, 26, 171-178.

Monge-Nájera, J., \& Morera-Brenes, B. (2015). Velvet worms (Onychophora) in folklore and art: geographic pattern, types of cultural reference and public perception. British Journal of Education, Society \& Behavioral Science, 10(3): 19. DOI: $10.9734 /$ bjesbs/2015/18945

Morera-Brenes, B. (2012). Los onicóforos, fósiles caminantes. El Salvador Ciencia \& Tecnología, 17(23), 8-13.

Mycotae. (19 de mayo de 2019). Lactarius indigo, for mayshroom [Dibujo animado en blog de arte]. Recuperado de https://rustandsky.tumblr.com/post/184999949095/lactarius-indigo-for-mayshroom

NosoyRidley. (6 de abril de 2016). Velvet Wyrm [Dibujo animado en blog de arte]. Recuperado de https://www.deviantart.com/nosoyridley/art/Velvet-Wyrm-601409228

Palacios-Vargas, J. G. (2011). Entomofilatelia: Las estampillas postales con insectos y otros artrópodos en el mundo. En: J.L. Navarrete-Heredia, G. Castaño-Meneses, \& G.A. Quiroz-Rocha (Eds.), Facetas de la Ciencia: Ensayos sobre Entomología Cultural (pp. 15-16). Recuperado de https://insectosuson.files.wordpress.com/2012/02/entomologia_cultural_np.pdf

Popcornflavoredtea. (2 de febrero de 2018). Chumky boi [Dibujo animado en blog de arte]. Recuperado de https://www.deviantart.com/popcornflavoredtea/art/Chumky-boi-728946363

Read, V. S. J., \& Hughes, R. N. (1987). Feeding behaviour and prey choice in Macroperipatus torquatus (Onychophora). Proceedings of the Royal society of London. Series B. Biological sciences, 230(1261), 483-506. DOI: $\underline{10.1098 / \mathrm{rspb} .1987 .0030}$

Salcedo, M. (2012). El antropomorfismo como herramienta de divulgación científica por televisión: estudio de El Hombre y la Tierra. Comunicación y Sociedad, 24(1), 217-246.

Santiago-Álvarez, C. (2014). La presencia de animales invertebrados en las paremias españolas. Paremia, 23, 121-133.

SkarmorySilver. (23 de octubre de 2018). 120 - ECLOPAKA [Dibujo animado en blog de arte]. Recuperado de https://www.deviantart.com/skarmorysilver/art/120-ECLIPATUS-766032403

Sobeyondthis. (13 de abril de 2011). Relaxed Worm [Dibujo animado en blog de arte]. Recuperado de https://www.deviantart.com/sobeyondthis/art/Relaxed-Worm-204745879

Solaz, L. (2003). Literatura gótica. Espéculo. Revista de estudios literarios, 23. Recuperado de http://www.ucm.es/info/especulo/numero23/gotica.html 
Vasconcellos, A., Almeida, W. O., \& Souza, L. A. (2006). Onychophora in humid forests of northeastern Brazil. Brazilian Journal of Biology, 66(1A), 187-189. DOI: 10.1590/s1519-69842006000100024

Vázquez, J. L., \& Callejas, M. V. (2002). Odonatos en la manifestación cultural de los pueblos. Revista Chapingo. Serie ciencias forestales y del ambiente, 8(2), 119-124. DOI: 10.5154/r.rchscfa.crossmark-policy

Viesca-González, F.C., \& Romero-Contreras, A.T. (2009). La entomofagia en México. Algunos aspectos culturales. El Periplo Sustentable. Turismo y Desarrollo, 16, 57-83. DOI: 10.21854/eps.v0i16.922

\section{APÉNDICE 1}

Los datos que apoyan los resultados de esta investigación están disponibles para su consulta en zenodo.org a través del enlace $\underline{10.5281 / \text { zenodo.3571445 }}$ 